\title{
Overdiagnosis of asthma in the community
}

\author{
Jorin LindenSmith $\mathrm{MD}^{1}$, Debra Morrison MD FRCPC FCCP ${ }^{1,2}$, Carole Deveau $\mathrm{MD}^{1}$, Paul Hernandez MDCM FRCPC ${ }^{1,2}$
}

J LindenSmith, D Morrison, C Deveau, P Hernandez. Overdiagnosis of asthma in the community. Can Respir J 2004;11(2):111-116.

BACKGROUND: Overdiagnosis of asthma may be an emerging problem after years of attention to the rising prevalence and reported underdiagnosis of the disease.

OBJECTIVES: A sample of adult asthmatics from the community was investigated to determine whether they met the current diagnostic criteria for asthma.

METHODS: Ninety participants were studied from a self-referred sample of physician-labelled, adult asthmatics from the community. The setting was a tertiary care, university-affiliated teaching hospital in Halifax, Nova Scotia. Three diagnostic criteria from the Canadian Thoracic Society Asthma Guidelines were used to demonstrate the presence of asthma: first, positive symptom history, and either, second, reversible airflow obstruction demonstrable on spirometry or documented peak expiratory flow rate diurnal variability, or, third, bronchial hyperreactivity to methacholine.

RESULTS: At the time of the study, $41 \%$ of a sample of physicianlabelled asthmatics showed no evidence of reversible airflow obstruction and had a negative methacholine challenge. By backward logistical regression analysis, a higher mean number of medications used $(\mathrm{P}<0.01)$, a lower forced expiratory volume in $1 \mathrm{~s}(\mathrm{P}<0.05)$ and using inhaled steroids $(\mathrm{P}<0.05)$ were predictive of meeting the diagnostic criteria for asthma. Sixty-two per cent of subjects who did not meet the criteria for asthma were currently taking medications for "asthma". Only $52.2 \%$ of the subjects reported ever having undergone pulmonary function testing.

CONCLUSIONS: Overdiagnosis of asthma is a potential problem, which may result in unnecessary or inappropriate medication use, increased health care costs and mislabelling of patients. The authors recommend greater use of objective diagnostic tests such as spirometry, peak flow diaries and bronchial provocation to establish a clinical diagnosis of asthma.

Key Words: Asthma; Diagnosis; Epidemiology; Respiratory function tests

\section{Le surdiagnostic de l'asthme dans la collectivité}

HISTORIQUE : Le surdiagnostic de l'asthme pourrait être un problème émergent après des années d'attention envers la prévalence croissante et le sous-diagnostic déclaré de la maladie.

OBJECTIFS : Un échantillon d'asthmatiques adultes de la collectivité a fait l'objet d'examens afin de déterminer s'ils respectent les critères diagnostiques courants de l'asthme.

MÉTHODOLOGIE : Quatre-vingt-dix participants ont été étudiés à partir d'un échantillon auto-aiguillé d'asthmatiques adultes diagnostiqués par un médecin et provenant de la collectivité. Cette étude a eu lieu dans un hôpital d'enseignement universitaire de soins tertiaires de Halifax, en Nouvelle-Écosse. Trois critères diagnostiques des principes directeurs sur l'asthme de la Société canadienne de thoracologie ont été utilisés pour démontrer la présence d'asthme : premièrement, des antécédents de symptômes positifs et, deuxièmement, soit un obstacle réversible à l'écoulement de l'air démontrable à la spirométrie, soit une variabilité diurne documentée du débit maximal respiratoire ou, troisièmement, une hyperréactivité bronchique à la méthacholine.

RÉSULTATS : Au moment de l'étude, 41\% de l'échantillon d'asthmatiques diagnostiqués par un médecin ne présentaient aucune trace d'obstruction réversible à l'écoulement de l'air, et leur épreuve à la méthacholine était négative. Au moyen d'une analyse de régression logistique inversée, un nombre moyen de médicaments utilisés plus élevé $(\mathrm{P}<0,01)$, un VEMS plus faible $(\mathrm{P}<0,05)$ et le recours à des stéroïdes en aérosol $(\mathrm{P}<0,05)$ étaient prédictifs du respect des critères diagnostiques de l'asthme. Soixante-deux pour cent des sujets qui ne respectaient pas les critères diagnostiques de l'asthme prenaient des médicaments " pour l'asthme ». Seulement $52,2 \%$ des sujets avaient déclaré avoir déjà subi une exploration fonctionnelle respiratoire.

CONCLUSIONS : Le surdiagnostic de l'asthme est un problème potentiel, qui peut entraîner l'usage de médicaments inutiles ou de complaisance, un accroissement des coûts de santé et un mauvais diagnostic des patients. Les auteurs recommandent un plus grand recours à des examens diagnostiques objectifs tels que la spirométrie, les carnets de débit de pointe et la provocation bronchique pour établir un diagnostic clinique d'asthme.

\footnotetext{
A sthma affects $5 \%$ to $10 \%$ of the population; its prevalence and mortality continue to increase (1-3). The disease is a significant cause of morbidity with regular use of medication and health care spending estimated at $\$ 504$ to $\$ 648$ million/year in Canada (4). In the past, underdiagnosis of asthma by primary care physicians has been reported as an important problem (5-8). However, the intense focus on asthma as a prevalent and treatable condition over the past decade may have resulted in a heightened awareness among physicians and led to asthma becoming a more frequent diagnosis.
}

Unfortunately, an increase in the index of suspicion for asthma in adults with respiratory complaints may also have led to mislabelling of nonasthmatics with the disease. There has been some attention in the popular media on the overdiagnosis of asthma, and other studies have alluded to this emerging clinical problem $(9,10)$. One published study has attempted to quantify the degree of misdiagnosis (11).

Inappropriate diagnosis of asthma is most likely to occur when physicians rely on clinical evaluation alone rather than objective testing. Asthma has been defined by the Canadian

${ }^{1}$ Faculty of Medicine, Dalhousie University; ${ }^{2}$ Respirology Division, Department of Medicine, Capital District Health Authority, Halifax, Nova Scotia Correspondence and reprints: Dr Paul Hernandez, 4458 Halifax Infirmary, 1796 Summer Street, Halifax, Nova Scotia B3H 3 A7.

Telephone 902-473-3698, fax 902-473-6202, e-mail Paul.Hernandez@cdha.nshealth.ca 
Thoracic Society (CTS) as an inflammatory disorder of the airways characterised by, first, paroxysmal or persistent symptoms (dyspnea, chest tightness, wheeze and cough), with, second, variable airflow limitation and, third, airway hyper-responsiveness to a variety of stimuli (12). Presumably, individuals not meeting these criteria may not suffer from the disease.

We prospectively studied a self-referred sample of 90 physician-labelled, adult asthmatics from the community to determine what proportion met the CTS criteria for the diagnosis of asthma to determine the extent of and risk factors associated with mislabelling.

\section{Subjects and asthma history}

\section{METHODS}

Subjects were recruited from the community using posters distributed throughout the Halifax regional municipality in Nova Scotia and advertisements in the local media. The advertisements asked for individuals with a prior diagnosis of asthma made by a physician to contact a respirology research co-ordinator if they were interested in participating in a research study about asthma. To be included in the study, subjects, either male or female, were required to be between 18 and 70 years old and to have been diagnosed by a physician as having asthma. Subjects were excluded if they had a serious underlying health condition that could influence study results, had had a lower respiratory tract infection within the previous six weeks, had a greater than 10 pack-year smoking history or were unable to perform the study procedures.

Informed written consent was obtained from each participant. The Research Ethics Committee of the Queen Elizabeth II Health Sciences Centre, Halifax, Nova Scotia, approved the study in accordance with the Canadian Tri-Council Guidelines and institutional policies for ethical conduct of research in human subjects.

Information concerning subject demographics, current antiasthma medications, previous pulmonary function tests, time diagnosed with asthma, nasal allergies, smoking history and previous referral to a specialist (ie, respirologist, internist, allergist or pediatrician) were collected. A modified Burney Asthma Questionnaire (13) dealing with respiratory symptoms over the previous 12 months (wheeze, dyspnea and cough) was administered.

\section{Pulmonary function testing}

All study procedures were performed between the months of June and September for three years (1998 to 2000). Spirometry was performed according to American Thoracic Society standards (14) using an S500/600 spirometer (Spirotech, Graseby Anderson, USA). Reference spirometry values used were those established by Crapo et al (15). The best of three acceptable measurements of forced expiratory volume in $1 \mathrm{~s}\left(\mathrm{FEV}_{1}\right)$, forced vital capacity and peak expiratory flow rate (PEFR) were recorded, with the two highest measurements differing by no more than $0.200 \mathrm{~L}$. Postbronchodilator response was assessed $15 \mathrm{~min}$ after inhalation of $400 \mu \mathrm{g}$ of salbutamol, delivered by metered-dose inhaler using a spacer device. Subjects were instructed to refrain from the use of short-acting beta agonists for $8 \mathrm{~h}$, long-acting bronchodilators for $48 \mathrm{~h}$ or theophylline preparations for $48 \mathrm{~h}$ before spirometry testing.
Subjects not demonstrating significant (ie, $12 \%$ or greater and $0.200 \mathrm{~L}$ or greater) improvement postbronchodilator were asked to record daily PEFRs over a period of two weeks. Subjects were instructed to perform three measurements with a peak flow meter (mini-Wright, Clement Clarke International, United Kingdom; or Vitalograph, Vitalograph Inc, USA) every morning and evening, and to record these values in a diary along with symptom scores and the number of inhalations of short-acting beta $_{2}$-agonist taken that day. The best values of each daily set of three measurements were used to ascertain PEFR variability, which was calculated as:

(higher [of morning or evening] - lower)/higher $\times 100 \%$

Methacholine inhalation challenges (MCs) were performed on all subjects according to the tidal breathing method described by Juniper et al (16), with an $\mathrm{FEV}_{1}$ of $70 \%$ or greater predicted. Medications withheld before the test were shortacting beta ${ }_{2}$-agonists for $8 \mathrm{~h}$, long-acting bronchodilators for three days, antihistamines for four days to six weeks (depending on the preparation) and theophylline preparations or leukotriene antagonists for $48 \mathrm{~h}$. Subjects were also asked to abstain from smoking, as well as consuming coffee, tea, cola and chocolate for $6 \mathrm{~h}$; significant exercise and cold air exposure were to be avoided for $2 \mathrm{~h}$ before testing. Inhaled corticosteroids were not routinely withheld.

\section{Diagnostic criteria}

Asthma was diagnosed according to CTS recommendations (12):

- A positive history (ie, an affirmative response for one question or more on the Modified Burney Asthma Questionnaire [Table 1]);

And one of the following:

- Documented reversible airflow obstruction either by demonstration of reversibility on spirometric testing (defined as an increase in $\mathrm{FEV}_{1}$ of $12 \%$ or greater and $0.200 \mathrm{~L}$ postbronchodilator) or diurnal variability on PEFR of $20 \%$ or greater on three days over a span of seven days; or

- Airway hyper-responsiveness, defined as the provocative concentration of methacholine resulting in at least a $20 \%$ fall in $\mathrm{FEV}_{1}$ compared with baseline $\left(\mathrm{PC}_{20}\right)$ of $8.0 \mathrm{mg} / \mathrm{mL}$ or less during provocation testing in subjects with an $\mathrm{FEV}_{1}$ of $70 \%$ or greater of predicted.

\section{Statistical analysis}

The clinical and demographic data are presented using descriptive statistics (mean \pm SD). Univariate analyses of subject characteristics were completed using Student's $t$ test for continuous variables and Fisher's exact test (two-tailed) for categorical variables. Logistical regression analysis was performed by the backward elimination technique to identify variables predictive of meeting the diagnostic criteria for asthma. A P value of less than 0.05 was considered to be statistically significant. 
TABLE 1

Univariate analyses of the positive response rate for each questionnaire item* in a study of a self-referred sample of 90 physician-labelled, adult asthmatics from the community to determine what proportion met the Canadian Thoracic Society criteria for the diagnosis of asthma

\begin{tabular}{|c|c|c|c|c|}
\hline & $\begin{array}{c}\text { All subjects } \\
(n=90)(\%)\end{array}$ & $\begin{array}{c}\text { Met criteria } \\
(n=53)(\%)\end{array}$ & $\begin{array}{c}\text { Did not meet criteria } \\
(n=37)(\%)\end{array}$ & $P$ \\
\hline 1. Have you had wheezing or whistling in your chest any time in past 12 months? & 93.3 & 96.2 & 89.2 & 0.224 \\
\hline 1a. Have you been at all breathless when the wheezing noise was present? & 81.1 & 84.9 & 75.7 & 0.288 \\
\hline 1b. Have you had this wheezing or whistling when you did not have a cold? & 86.7 & 90.6 & 81.1 & 0.220 \\
\hline 2. Have you woken up with a feeling of tightness in your chest at any time in the past 12 months? & 57.8 & 62.3 & 51.4 & 0.386 \\
\hline 3. Have you been woken by an attack of shortness of breath at any time in the past 12 months? & 45.6 & 50.9 & 37.8 & 0.283 \\
\hline 4. Have you been woken by an attack of coughing at any time in the past 12 months? & 61.1 & 60.4 & 62.2 & 1.000 \\
\hline 5. Have you had an attack of asthma in the past 12 months? & 70.0 & 79.3 & 56.8 & 0.035 \\
\hline
\end{tabular}

${ }^{*}$ Questions based on modified Burney Asthma Questionnaire (13)

\section{RESULTS}

In total, 99 subjects were recruited for the study. One subject was unable to participate due to poor comprehension of the spirometry manoeuvre and was excluded from further study. Two subjects felt unable to discontinue antihistamine medications to perform the MC. Six subjects did not return for the second appointment to complete the MC and could not be contacted for follow-up. These eight subjects all had normal spirometry results.

Ninety subjects completed the study as per protocol. Two of these subjects had an $\mathrm{FEV}_{1}$ of less than $70 \%$ predicted and thus were not eligible for MC. Because both subjects showed evidence of variable airflow obstruction on spirometry testing (improvement in $\mathrm{FEV}_{1}$ of $12 \%$ and $0.20 \mathrm{~L}$ or greater), they met the diagnostic criteria for asthma on this basis. They were grouped with the subjects with positive MC results for data analysis purposes.

Table 2 shows the results for subjects meeting the three diagnostic criteria for asthma. Forty-one per cent of subjects did not meet the CTS criteria for the diagnosis of asthma at the time of testing. The majority of subjects (37 of 39) who met the diagnostic criteria for asthma did so on the basis of a positive history and $\mathrm{MC}$ (with or without documented variable airflow obstruction demonstrated by spirometry reversibility or PEFR variability). Only two additional subjects met the diagnostic criteria for asthma on the basis of positive history and variable airflow obstruction alone. Univariate analyses of subject characteristics compared by the fulfilment of the diagnostic criteria is shown in Tables 1 and 3. All subjects reported being recently symptomatic, although to a variable degree, at the time of their involvement in the study. All subjects reported affirmatively to at least one question from the Modified Burney Asthma Questionnaire (Table 1), including $93.3 \%$ who reported wheezing and $70 \%$ who reported experiencing an "asthma attack" in the previous 12 months.

Univariate analyses showed that lower $\mathrm{FEV}_{1}$, regular use of medications, higher mean number of medications used, longer time since diagnosis and a self-described "asthma attack" in the previous 12 months were predictive of meeting the diagnostic criteria for asthma.

By backward logistical regression analysis, higher mean number of medications used $(\mathrm{P}=0.006)$, lower $\mathrm{FEV}_{1}(\mathrm{P}=0.018)$ and use of inhaled corticosteroids $(\mathrm{P}=0.05)$ were predictive of meeting the diagnostic criteria for asthma.

Seven subjects responded to the methacholine challenge with a $\mathrm{PC}_{20}$ of between 0 and $0.25 \mathrm{mg} / \mathrm{mL}, 22$ subjects had a $\mathrm{PC}_{20}$ of between 0.25 and $2.0 \mathrm{mg} / \mathrm{mL}$ and 20 subjects responded
TABLE 2

Per cent of subjects fulfilling diagnostic criteria for asthma from the Canadian Thoracic Society (12)

\begin{tabular}{lc}
\hline Diagnostic criteria & $\begin{array}{c}\text { Per cent of } \\
\text { subjects }(\mathbf{n}=\mathbf{9 0})\end{array}$ \\
\hline 1. Positive symptom history & 100.0 \\
2. Variable airflow obstruction & 28.9 \\
$\quad$ Spirometry reversibility & 22.2 \\
Peak expiratory flow rate variability & 6.7 \\
3. Positive MC $\left(\mathrm{PC}_{20} \leq 8 \mathrm{mg} / \mathrm{mL}\right)$ & 56.7 \\
4. Both variable airflow obstruction and positive MC & 26.7 \\
5. Positive history and variable airflow obstruction or positive MC & 58.9
\end{tabular}

MC Methacholine inhalation challenge; $P C_{20}$ Provocative concentration of methacholine resulting in $20 \%$ fall in forced expiratory volume in $1 \mathrm{~s} \mathrm{com-}$ pared with baseline

with a $\mathrm{PC}_{20}$ of between 2.0 and $8.0 \mathrm{mg} / \mathrm{mL}$. Four subjects responded to methacholine at doses greater than $8 \mathrm{mg} / \mathrm{mL}$ but less than $16 \mathrm{mg} / \mathrm{mL}$, which, although is within the 'grey zone', was considered a negative result for bronchial hyper-reactivity.

Repeating the statistical analysis with the removal of subjects who reported regularly using inhaled corticosteroids $(n=45)$ did not significantly alter the results in that a higher mean number of medications used and a lower $\mathrm{FEV}_{1}$ were still predictive of meeting the diagnosis of asthma.

\section{DISCUSSION}

In a sample population of physician-labelled asthmatics, at the time of study testing, $41 \%$ did not meet the CTS criteria for the diagnosis of asthma. There were no significant differences between subjects with respect to age, sex, smoking history or prior specialist referral. Logistical regression analysis revealed that a higher mean number of medications used, a lower $\mathrm{FEV}_{1}$ and use of inhaled corticosteroids were predictive of meeting the diagnostic criteria for asthma.

A recent study by Joyce et al (9) examined a heterogeneous referred sample of patients sent for $\mathrm{MC}$ by pulmonologists. They reported that of the 175 patients with negative $\mathrm{MC}$ results (defined as a $\mathrm{PC}_{20}$ of greater than $8.0 \mathrm{mg} / \mathrm{mL}$ ), $74 \%$ had been previously labelled as asthmatic by their primary care physician. This study raised the possibility of frequent misdiagnosis of asthma in the general population. Joyce et al's study differs from our own in that their sample was a referred population to pulmonologists, with a variety of diagnoses, including asthma, and likely represented 
TABLE 3

Univariate analyses of subject characteristics in a study of a self-referred sample of 90 physician-labelled, adult asthmatics from the community to determine what proportion met the CTS criteria for the diagnosis of asthma

\begin{tabular}{|c|c|c|c|c|}
\hline Characteristic & All subjects & $\begin{array}{l}\text { Met CTS criteria } \\
(n=90)\end{array}$ & $\begin{array}{l}\text { Did not meet CTS criteria } \\
\qquad(\mathrm{n}=53)\end{array}$ & $P(n=37)$ \\
\hline Age in years (mean $\pm S D$ ) & $33.6 \pm 11.4$ & $34.5 \pm 12.3$ & $32.3 \pm 10.2$ & 0.373 \\
\hline \multicolumn{5}{|l|}{$\operatorname{Sex}(\%)$} \\
\hline Female & 66.7 & 69.8 & 62.2 & 0.304 \\
\hline Male & 33.3 & 30.2 & 37.8 & \\
\hline \multicolumn{5}{|l|}{ Spirometry (\% predicted) } \\
\hline Forced expiratory volume in $1 \mathrm{~s}$ (mean \pm SD) & $94.8 \pm 16.7$ & $91.3 \pm 16.6$ & $100.0 \pm 15.6$ & 0.014 \\
\hline Forced vital capacity (mean \pm SD) & $103.3 \pm 13.8$ & $102.2 \pm 14.0$ & $104.9 \pm 13.6$ & 0.360 \\
\hline Medication use (\%) & 75.6 & 84.9 & 62.2 & 0.024 \\
\hline Inhaled beta ${ }_{2}$-agonist & 75.6 & 84.9 & 62.2 & 0.024 \\
\hline Inhaled corticosteroid & 50.0 & 54.7 & 43.2 & 0.392 \\
\hline Number of asthma medications (mean $\pm \mathrm{SD}$ ) & $1.5 \pm 1.0$ & $1.7 \pm 0.9$ & $1.2 \pm 0.9$ & 0.009 \\
\hline Nasal allergies (\%) & 70.0 & 73.6 & 64.9 & 0.484 \\
\hline Prior pulmonary function tests (\%) & 47.0 & 49.1 & 56.8 & 0.524 \\
\hline Past specialist referral $(\%)$ & 51.1 & 52.8 & 48.7 & 0.831 \\
\hline Years since diagnosis (mean \pm SD) & $13.4 \pm 11.1$ & $15.7 \pm 11.6$ & $10.2 \pm 9.5$ & 0.020 \\
\hline Smoking history in pack-years (mean \pm SD) & $1.4 \pm 2.9$ & $1.2 \pm 2.8$ & $1.8 \pm 3.2$ & 0.345 \\
\hline
\end{tabular}

CTS Canadian Thoracic Society

cases difficult to treat or those with uncertain diagnoses. Our study examined a sample of self-referred asthmatics in the community, only $55 \%$ of whom had ever seen an asthma specialist.

Kolnaar et al (17) published a study investigating the diagnosis of asthma in a general practice population. Of the population screened, $8.3 \%$ had a prior diagnosis of asthma. Using diagnostic criteria similar to those used in our study, only $50 \%$ of their physician-labelled patients fulfilled the diagnostic criteria for asthma.

The literature contains other references to the potential overdiagnosis of asthma. Pratter et al (18) examined 34 patients referred with wheeze and found that a prior diagnosis of asthma was predictive of having asthma (defined as positive history and positive $\mathrm{MC}$ ) in only $62 \%$ of the sample. While this study investigated a population of patients who had been referred to a specialist, the extent of possible overdiagnosis of asthma is quite consistent with our own study. Dzyngel et al (19) reported that 55 of 399 patients $(14 \%)$ seen for asthma in an ambulatory care asthma program were subsequently determined not to suffer from this disorder.

Marklund et al (11) examined patients with the label of asthma from the practice of two family practitioners. A history was taken and spirometry was performed for all asthmatic patients. The patients for whom the diagnosis remained uncertain (according to the treating physicians) had spirometry repeated after two weeks of oral prednisolone. If spirometry results were normal, the patients underwent an $\mathrm{MC}$ or exercise test. Smokers were included in the sample, and a positive history alone was sufficient for the diagnosis of asthma. Despite this broader definition, $37 \%$ of the patient population did not meet the criteria for asthma. In contrast, our study reflects a more community-wide sample of asthma diagnosis, rather than the practice of a few individual family physicians.

There are several possible sources of bias inherent in the design of our study. The recruitment of subjects was achieved using advertisements in local media and postings throughout the local community. It is possible that the characteristics of responders differed from those of the general asthmatic population. This could have biased our sample, for example, by attracting more severe asthmatics who were eager to contribute toward research on their disabling condition, or alternatively, by attracting asthmatics who were sceptical of their diagnosis and desired another opinion or objective testing. Because subjects were self-referred in this study, it is possible that they had not, in fact, been labelled by a physician as having asthma. Some people in the general population label themselves as having asthma, although they have not actually received this diagnosis from a physician $(20,21)$. There is confusion in the lay population equating wheeze with asthma; however, the prevalence of wheeze exceeds that of asthma (20). Inappropriate self-referral may have been limited in this study, because all potential subjects were made aware that test results would be sent to their family physicians at the time of study completion. In addition, $75.6 \%$ of subjects had received a prescription for an inhaled medication within the previous year.

Although the criteria that we used represented CTS consensus guidelines on the diagnosis of asthma, it is possible that some true asthmatics did not have a $\mathrm{PC}_{20}$ of $8 \mathrm{mg} / \mathrm{mL}$ or less, or did not have demonstrable variable airflow obstruction at the time of their participation in the study. The diagnostic value of bronchoprovocation studies in combination with symptom history in asthmatic individuals with normal spirometry results has been well established (22). We defined a positive $\mathrm{MC}$ as a $\mathrm{PC}_{20}$ of $8 \mathrm{mg} / \mathrm{mL}$ or less, because the sensitivity and specificity of $\mathrm{PC}_{20}$ in the diagnosis of asthma are reported to be $100 \%$ and $93 \%$, respectively, when using this cut-off (23). However, response to $\mathrm{MC}$ can vary within the same individual at different times (24). Purely seasonal asthmatics may have a normal MC result if tested at a time when not exposed to allergens (25). Although this situation would be less common during the summer months when our study was performed, it may have resulted in overestimation of the false-positive rate of asthma. Although subjects reported being recently symptomatic, these symptoms may not have been related to asthma. Therefore, individuals with mild asthma and intermittent air- 
way hyper-responsiveness may have been assessed during a clinically stable period, consequently having false-negative test results.

Inhaled corticosteroid use can alter sensitivity to methacholine and peak flow variability. We did not require subjects to stop taking their inhaled corticosteroids during the peak flow testing period, which may have reduced the incidence and degree of peak flow variability. Also, subjects with mild asthma taking inhaled corticosteroids may have shifted their $\mathrm{MC}$ results from a $\mathrm{PC}_{20}$ of less than $8 \mathrm{mg} / \mathrm{mL}$ to greater than $8 \mathrm{mg} / \mathrm{mL}$, leading to a false-negative result. However, in terms of bronchial provocation, the mean $\mathrm{PC}_{20}$ of subjects taking inhaled corticosteroids was actually lower than that of those not taking inhaled corticosteroids. Additionally, when subjects taking inhaled corticosteroids were removed from the analysis, the results were unchanged in terms of the predictors of meeting the diagnosis of asthma.

It would have been interesting to repeat the study procedures in subjects who did not initially meet the diagnostic criteria for asthma after a period of time without taking inhaled corticosteroids. Mild asthmatics with initial false-negative test results may have been identified. As well, because this was a study of self-referred individuals with asthma, a chart review from their family physicians may have been helpful to confirm that they truly had been diagnosed with this condition.

Positive MC results can occur with acute upper respiratory tract infection (26), allergic rhinitis (27) and adult respiratory distress syndrome (28). We excluded subjects who reported having a recent upper respiratory tract infection or another significant disease. Our definition of asthma included multiple criteria and did not rely solely on the results of MC testing to establish the diagnosis; however, the possible inclusion of subjects with unrecognized allergic rhinitis without asthma may have resulted in underestimation of the false-positive rate for asthma diagnosis.

Overdiagnosis is problematic for many reasons. The label of asthma carries with it significant psychological, social and lifestyle burdens. Asthmatic patients are labelled with a chronic, incurable disease and often face a lifetime of avoiding triggers for their condition (29). Asthma consumes significant health care dollars in Canada and worldwide. In addition to the effect of the diagnosis on the patients' ability to obtain insurance, regular use of antiasthma medications is costly and imposes unnecessary financial burdens on those for whom treatment is not warranted.

The long-term effects of treatment with antiasthma medications are another concern. Seventy-five per cent of our subjects were taking regular medications for asthma at the time of the study, including $58 \%$ of subjects who did not meet the diagnostic criteria. Subjects who met the diagnostic criteria used a higher average number of medications $(\mathrm{P}<0.05)$. Of the subjects who did not meet the diagnostic criteria, bronchodilator medication was taken regularly by $62 \%$, and $43 \%$ regularly used inhaled corticosteroids. However, there was no statistically significant difference in reported inhaled corticosteroid use among those potentially mislabelled with asthma compared with those who met the diagnostic criteria. Because the adverse effects of inhaled corticosteroids range from oropharyngeal candidiasis and dysphonia to potential systemic effects (30), unnecessary use may pose a health risk to the patient.

In addition to the burdens imposed on normal individuals by an incorrect diagnosis of asthma, there is a possibility that other respiratory or nonrespiratory illnesses were being incorrectly labelled as asthma and were not appropriately investigated or treated. Although the results of the procedures performed in this study were forwarded to the subjects' family physicians, no additional attempt was made by the study investigators to identify an alternative diagnosis in those who did not meet diagnostic criteria for asthma.

The 1995 Nova Scotia Health Survey reported an 8\% prevalence of self-reported asthma in the province. The epidemiology of asthma reflects, to some extent, clinical practice, as well as the true prevalence of the disease (31). Overdiagnosis may be one factor contributing to the rising prevalence of asthma. Hay and Higenbottam (7) have suggested that the significant increase in diagnosed asthmatics results from improved diagnosis, rather than a real change in disease prevalence. Manfreda et al (32) has reported a doubling of asthma diagnosis in Canada during the 1980s and proposed diagnostic exchange (ie, reclassification of bronchitis and COPD to asthma) as an additional explanation contributing to the increasing prevalence of asthma.

The high prevalence of incorrect labelling of nonasthmatics in our study suggests that despite recent guidelines, many physicians continue to rely on clinical evaluation alone when establishing a diagnosis. Only 58\% of our study subjects reported having previously undergone pulmonary function testing of any kind. Only one subject reported having previously undergone MC testing.

It is evident from our data that spirometry and peak flow measurements often fail to confirm the presence of asthma. In $64 \%$ of our subjects with positive responses to MC, initial spirometry was normal; there was no reversibility postbronchodilator, and peak flow monitoring over a two-week period did not demonstrate variable airflow obstruction. The authors recommend that $\mathrm{MC}$ be considered in patients in whom the diagnosis of asthma is suspected based on clinical presentation, but who do not have reversible airflow obstruction evident on spirometry or peak flow rate measurements.

\section{CONCLUSIONS}

Previous attention to the underdiagnosis and undertreatment of asthma, combined with literature indicating increasing prevalence of the condition, have led to greater awareness of this disease entity. A higher index of suspicion for asthma may have contributed to increased labelling based on clinical suspicion alone without confirmation by objective testing. In our study, $41 \%$ of a self-referred, community sample of physicianlabelled, adult asthmatics did not meet the diagnostic criteria for asthma at the time of their participation in the study. Overdiagnosis could be minimized by the use of appropriate diagnostic tests. These data and previous literature support the CTS recommendation that the clinical diagnosis of asthma should be confirmed by objective testing.

ACKNOWLEDGEMENTS: The authors would like to express their gratitude to Mr Wade Blanchard for his assistance with statistical analysis and to the pulmonary function laboratory staff at the Queen Elizabeth II Health Sciences Centre. This study was funded in part by the Legacy Research Fund, Lung Association of Nova Scotia. Jorin LindenSmith and Carole Deveau were recipients of Dalhousie University Internal Medicine Research Foundation Studentship grants. 


\section{REFERENCES}

1. Sears M. Descriptive epidemiology of asthma. Lancet 1997;350(Suppl II):1-4.

2. Beasley R, Keil U, von Mutius E, et al. Worldwide variation in prevalence of symptoms of asthma, allergic rhinoconjunctivitis, and atopic eczema: ISAAC. The International Study of Asthma and Allergies in Childhood (ISAAC) Steering Committee. Lancet 1998;351:1225-32.

3. Manfreda J, Becklake MR, Sears MR, et al. Prevalence of asthma symptoms among adults aged 20-44 years in Canada. CMAJ 2001;164:995-1001.

4. Krahn MD, Berka C, Langlois P, et al. Direct and indirect costs of asthma in Canada, 1990. Can Med Assoc J 1996;154:821-31.

5. Speight ANP, Lee DA, Hey EN. Underdiagnosis and undertreatment of asthma in childhood. BMJ 1983;286:1253-6.

6. Shee CD, Poole D, Cameron IR. Treatment of asthma in general practice. Thorax 1980;35:236.

7. Hay IFC, Higenbottam TW. Has the management of asthma improved? Lancet 1987;2:609-11.

8. Siersted HC, Boldsen J, Hansen HS, et al. Population based study of risk factors for underdiagnosis of asthma in adolescence: Odense schoolchild study. BMJ 1998;316:651-7.

9. Joyce DP, Chapman KR, Kesten SK. Prior diagnosis and treatment of patients with normal results of methacholine challenge and unexplained respiratory symptoms. Chest 1996;109:697-701.

10. Kesten S, Rebuck AS, Chapman KR. Trends in asthma and chronic obstructive pulmonary disease therapy in Canada, 1985 to 1990. J Allergy Clin Immunol 1993;92:499-506.

11. Marklund B, Tunsater A, Bengtsson C. How often is the diagnosis of bronchial asthma correct? Fam Pract 1999;16:112-6.

12. Ernst P, Fitzgerald JM, Spier S. Canadian Asthma Consensus Conference: Summary of recommendations. Can Respir J 1996;3:89-100.

13. Burney PGJ, Laitinen LA, Perdrizet S, et al. Validity and repeatability of the IUATLD 1984 Bronchial Symptoms Questionnaire: An international comparison. Eur Respir J 1989;2:940-5.

14. American Thoracic Society. Lung function testing: Selection of reference values and interpretative strategies. Am Rev Respir Dis 1991;144:1202-18.

15. Crapo RO, Morris AH, Gardner RM. Reference spirometric values using techniques and equipment that meet ATS recommendations. Am Rev Repir Dis 1981;123:659-64.

16. Juniper EF, Cockcroft DW, Hargreave FE. Histamine and Methacholine Inhalation Tests: Tidal Breathing Method. Laboratory
Procedure and Standardisation. Canadian Thoracic Society. Lund: AB Draco, 1991.

17. Kolnaar BGM, Beissel E, Van Den Bosch WJHM, et al. Asthma in adolescents and young adults: Screening outcome versus diagnosis in general practice. Fam Pract 1994;11:133-40.

18. Pratter MR, Hingston DM, Irwin RS. Diagnosis of bronchial asthma by clinical evaluation: An unreliable method. Chest 1983;84:42-7.

19. Dzyngel B, Kesten S, Chapman KR. Assessment of an ambulatory care asthma program. J Asthma 1994;31:291-300.

20. Dodge RB, Burrows B. The prevalence and incidence of asthma and asthma-like symptoms in a general population sample. Am Rev Respir Dis 1980;122:57-75.

21. Samet JM, Schrag SD, Howard CA, et al. Respiratory disease epidemiology in a New Mexico population sample of Hispanic and non-Hispanic whites. Am Rev Respir Dis 1982;125:152-7.

22. Adelroth E, Hargreave FE, Ramsdale EH. Do physicians need objective measurements to diagnose asthma? Am Rev Respir Dis 1986 134:704-7.

23. Cockcroft DW, Berscheid BA, Murdock KY, et al. Sensitivity and specificity of histamine $\mathrm{PC}_{20}$ measurements in a random selection of young college students. J Allergy Clin Immunol 1992;89:23-30.

24. Cockcroft DW. Bronchial inhalation tests. I. Measurement of nonallergic bronchial responsiveness. Ann Allergy 1985;55:527-34.

25. Cockcroft DW, Ruffin RE, Dolovich J. Allergen-induced increase in nonallergic bronchial reactivity. Clin Allergy 1977;7:503-13.

26. Parker CD, Bilbo RE, Reed CE. Methacholine aerosol as test for bronchial asthma. Arch Intern Med 1965;115:452-8.

27. Villacorte GV, Bewtra AK, Brodkey FD. Response to methacholine aerosol challenge - Comparison of normals from atopic and non-atopic families. Am Rev Respir Dis 1977;115:A77. (Abst)

28. Simpson DL, Goodman M, Spector SL. Long-term follow-up and bronchial reactivity testing in survivors of the adult respiratory distress syndrome. Am Rev Respir Dis 1978;117:449-54.

29. Juniper EF, Guyatt GH, Epstein RS. Evaluation of impairment of health related quality of life in asthma: Development of a questionnaire for use in clinical trials. Thorax 1992;47:76-83.

30. Hanania NA, Chapman KR, Kesten S. Adverse effects of inhaled corticosteroids. Am J Med 1995;98:196-205.

31. Dodge RR, Burrows B. The prevalence and incidence of asthma and asthma-like symptoms in a general population sample. Am Rev Respir Dis 1980;122:567-75.

32. Manfreda J, Becker AB, Wang P, et al. Trends in physician-diagnosed asthma prevalence in Manitoba between 1980 and 1990. Chest 1993;103:151-7. 


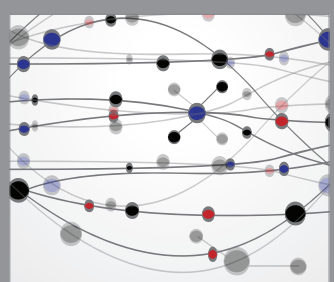

The Scientific World Journal
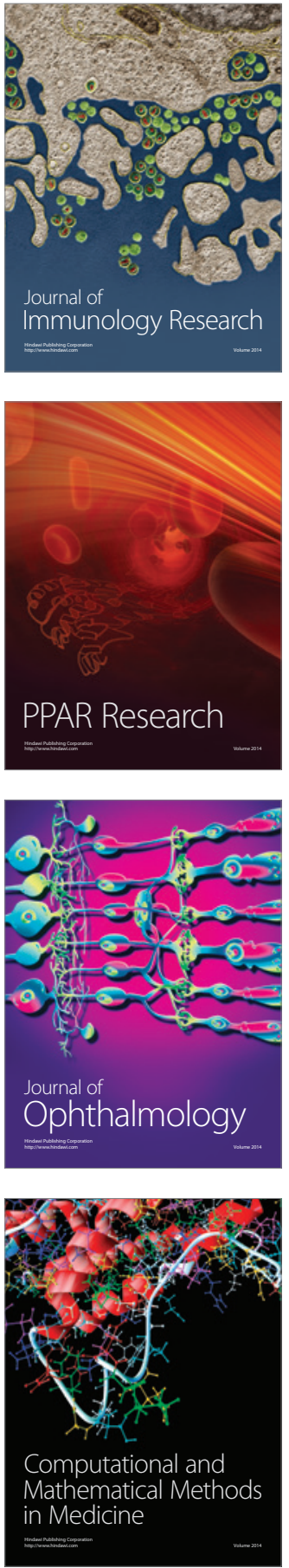

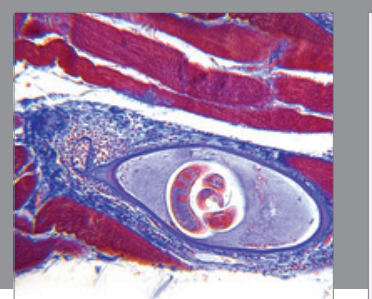

Gastroenterology Research and Practice

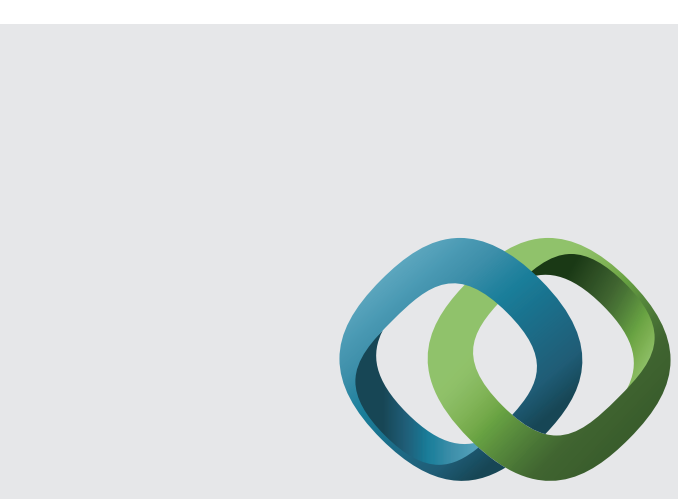

\section{Hindawi}

Submit your manuscripts at

http://www.hindawi.com
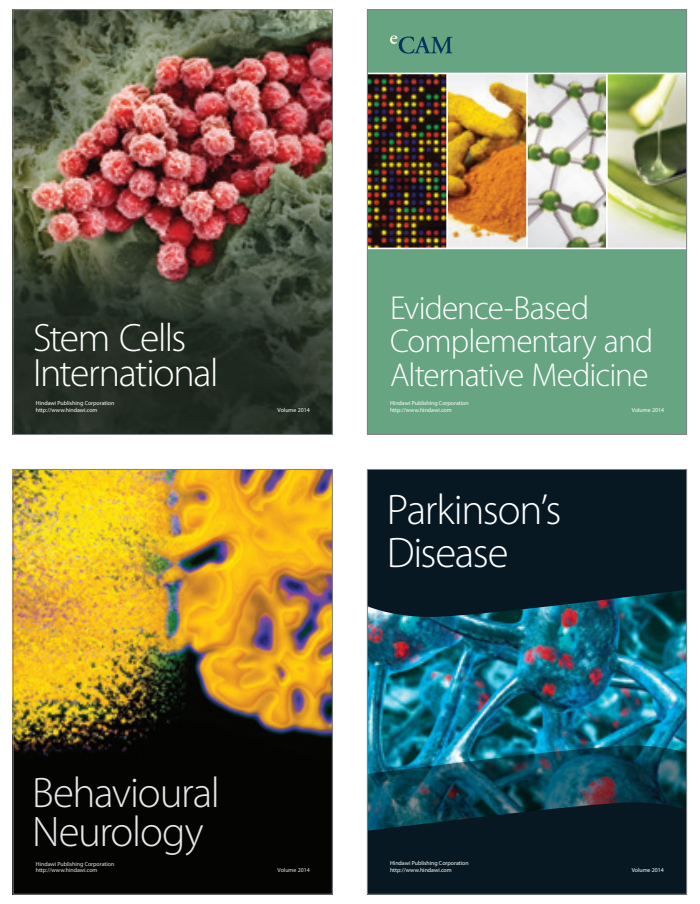
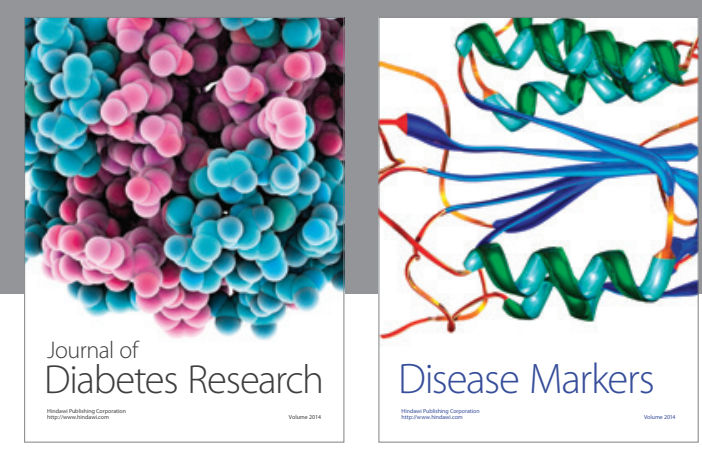

Disease Markers
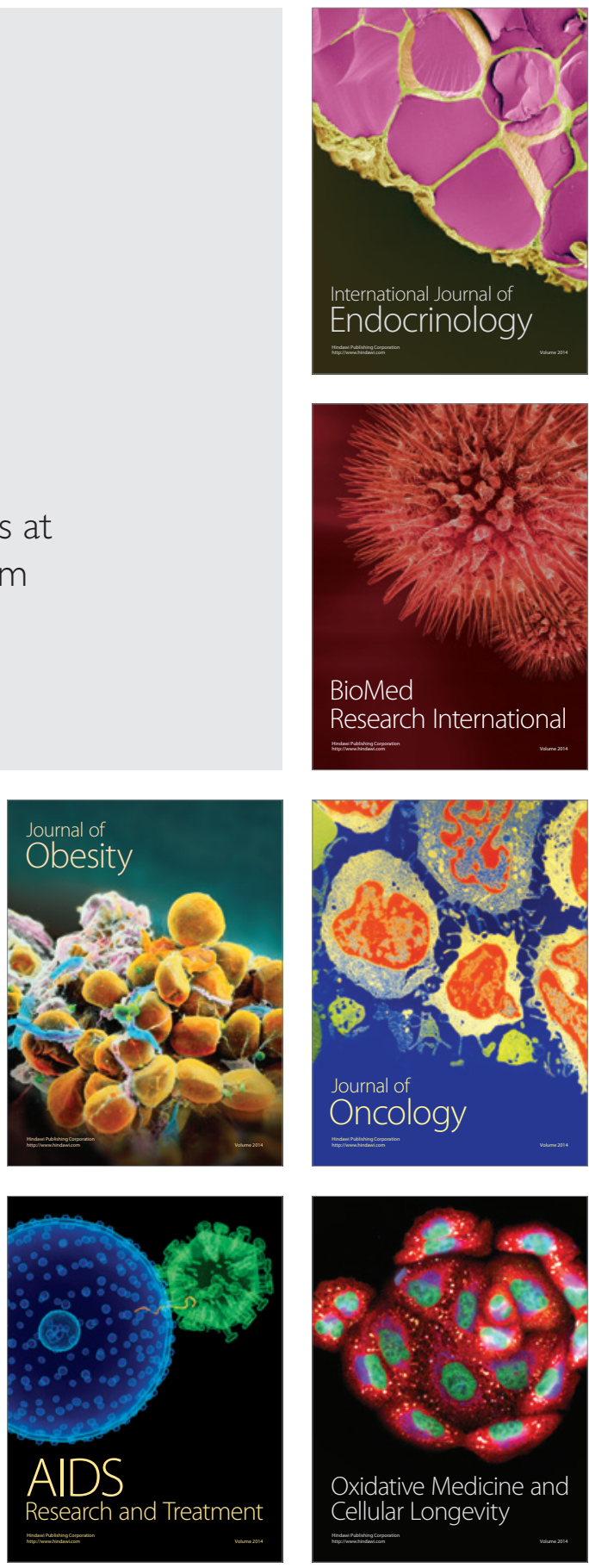